\title{
High-Density Polyethylene Based on Exfoliated Graphite Nanoplatelets/Nano-Magnesium Oxide: An Investigation of Thermal Properties and Morphology
}

\author{
A. I. Alateyah \\ Mechanical Engineering Department, Unaizah Engineering College, Qassim University, Unaizah, KSA \\ Email: aialateyah@gmail.com
}

How to cite this paper: Alateyah, A.I. (2019) High-Density Polyethylene Based on Exfoliated Graphite Nanoplatelets/NanoMagnesium Oxide: An Investigation of Thermal Properties and Morphology. Materials Sciences and Applications, 10, 159-169. https://doi.org/10.4236/msa.2019.103013

Received: January 31, 2019

Accepted: March 8, 2019

Published: March 11, 2019

Copyright () 2019 by author(s) and Scientific Research Publishing Inc. This work is licensed under the Creative Commons Attribution International License (CC BY 4.0). http://creativecommons.org/licenses/by/4.0/

\begin{abstract}
In this study, high-density polyethylene (HDPE)/exfoliated graphite nanoplatelet $(\mathrm{xGnP})$ composites reinforced with a $2 \mathrm{wt} . \%$ concentration of nanomagnesia $(\mathrm{n}-\mathrm{MgO})$ were fabricated using an injection moulding machine. The thermal properties and morphological structures of the composites were investigated. The XRD results showed the peaks of $\mathrm{xGnP}$ and $\mathrm{n}-\mathrm{MgO}$, where the intensity of the $\mathrm{xGnP}$ peaks became stronger with adding increasing amounts of $\mathrm{xGnP}$ into the polymermatrix. In terms of morphology, some agglomeration of particles was observed within the matrix, and the agglomeration decreased the thermal properties of the composites. The nanocomposites showed less thermal stability than the pristine polymer. The reduction in the onset temperature compared to that of neat HDPE was attributed to less adhesion between the fillers and the matrix. In addition, the crystallinity was reduced by the addition of fillers.
\end{abstract}

\section{Keywords}

High-Density Polyethylene, Exfoliated Graphite Nanoplatelets, Magnesium Oxide Nanoparticles, TGA, XRD, SEM

\section{Introduction}

In the last era, the plastic industry had witnessed rapid growth in the production of synthetic polymers such as polyethylene ( $\mathrm{PE}$ ), polypropylene (PP), polystyrene (PS), polyethylene terephthalate (PET), polyvinyl alcohol (PVA) and polyvinyl chloride (PVC). Accordingly, plastics have become inseparable and indispensable components of society. The use of plastics has significantly increased to 
meet the demands of society by enabling affordable manufacturing of numerous products for packaging, safety and protection, service, lightweight components in cars and aircraft, mobile phones, construction, medical devices, toys and other uses [1] [2]. Among the different types of polymers, high-density polyethylene (HDPE) plays a vital role in thermoplastic industries due to its superior physical and mechanical properties. However, the adoption of HDPE in structural applications is limited due to the need for better mechanical properties. To overcome this drawback, the mechanical properties of HDPE could be improved using different additives, such as glass fibre, carbon fibre, and carbon black, for reinforcement [3]. Recently, a new promising type of reinforcement, exfoliated graphite nanoplatelets ( $\mathrm{xGnPs}$ ), has been commonly used. The use of $\mathrm{xGnPs}$ for reinforcement has resulted in outstanding properties for HDPE matrices [3]-[9]. $\mathrm{xGnPs}$ are notable for having a semi-metallic character and are is commonly comprised of less than 10 layers of graphene with thicknesses that do not exceed a few nanometres, while their other two dimensions can reach up to a few hundred microns [10]. Additionally, $\mathrm{xGnP}$ is considered an ideal reinforcing material that enhances the thermal, mechanical and electrical properties of a polymeric matrix [11] [12]. Nanoparticle MgO materials are widely utilized metal oxides that can be easily synthesized using inexpensive raw materials such as brines, magnesium salts and magnesium-bearing minerals [13]. MgO materials are usually selected due to their superior properties, such as high strength, modulus, melting point, and hardness and exceptional thermodynamic stability. Accordingly, $\mathrm{MgO}$ was chosen to be used as a suitable reinforcement in this study [14].

The thermal degradation of polymers has been studied in recent decades [15]-[20]. Due to the low thermal degradation resistance of organic-based polymers, thermal stability is one of the most studied characteristics. Recent studies have stated that the addition of nanomaterials, such as carbon nanotubes, nanoclays, and graphene, to polymers would improve the thermal stability of a studied polymer. The incorporation of inorganic fillers, such as GNPs, has been shown to further enhance many of these properties, including thermal properties [21] [22]. Furthermore, studies discussing the adoption of $\mathrm{MgO}$ as ananofiller for HDPE-xGnP composites are very limited in the literature. Accordingly, the aim of this work is to investigate the thermal properties of HDPE-xGnP/n-MgO composites.

\section{Experimental Procedures and Methods}

\subsection{Materials}

$\mathrm{n}-\mathrm{MgO}$ and $\mathrm{xGnP}$ with a purity of $99.9 \%$ were used in this study as filler materials. The $\mathrm{n}-\mathrm{MgO}$ and $\mathrm{xGnP}$ were purchased from Tritrust Industrial Co., China. The $\mathrm{xGnP}$ has a diameter of $10 \mu \mathrm{m}$ and a thickness of $5 \mathrm{~nm}$, whereas the $\mathrm{MgO}$ nanoparticles have a particle size of $10 \mathrm{~nm}$. The HDPE matrix particles were supplied by SABIC, Kingdom of Saudi Arabia. 


\subsection{Fabrication of Composites}

In this study, the different weight percentages of $x \mathrm{GnP}$ and $\mathrm{n}-\mathrm{MgO}$ reinforcement used are shown in Table 1.

The weighed powders were mixed using a mechanical disperser to obtain a homogeneous distribution of the filler materials in the HDPE matrix. Subsequently, the mixed powders were put into a Battenfeld HM 1000/750 injection moulding machine to produce the samples. Injection moulding was carried out using an L/D ratio of 22, screw diameter of $45 \mathrm{~mm}$, a clamping force of 10 tons, barrel and nozzle temperatures of $230^{\circ} \mathrm{C}$, pressure of $3000 \mathrm{psi}$, and mould temperature of $20^{\circ} \mathrm{C}$. The different HDPE- $\mathrm{xGnP} / \mathrm{n}-\mathrm{MgO}$ composites shown in Table 1 were examined to investigate the effect on the thermal properties of HDPE-xGnP composites of the addition of n-MgO.

\subsection{X-Ray Diffraction Analysis (XRD)}

XRD (Schimadzu 7000, Japan) was used to confirm the existing phases of the composites. Wide-angle X-ray diffraction (WAXD) patterns, which provide the characteristics of the nanoparticles, were obtained with an X-ray diffractometer equipped with $\mathrm{CuK} \alpha$ radiation. The survey scan was run between $10^{\circ}$ and $90^{\circ}$ with a scanning speed of $2^{\circ}$ per minute.

\subsection{Scanning Electron Microscopy (SEM)}

The samples were prepared by fracturing (cryo-fracturing) the samples into 1 $\mathrm{cm}$ long pieces at the neck portion of tensile samples and attaching each to a 12.5 $\mathrm{mm}$ diameter $\mathrm{Al}$ stub with sticky $12 \mathrm{~mm}$ diameter $\mathrm{C}$ tabs. The samples were Au-Pd sputter-coated for $1-2$ minutes at a deposition current of $25 \mathrm{~mA}$ and a partial pressure of $\sim 0.1$ TorrAr. The samples were then transferred to be examined by SEM.

\subsection{Fourier Transform Infrared (FTIR)}

A spectrogram of the composite surface was collected using an FTIR 783 Perkin Elmer spectrometer. Each spectrum was obtained for 24 scans between 4000 and $400 \mathrm{~cm}^{-1}$ at intervals of $1 \mathrm{~cm}^{-1}$ with a resolution of $4 \mathrm{~cm}^{-1}$. An FTIR spectroscopic study was performed to assess the structural degradation of the immersed samples or changes in the chemical structure.

\subsection{Thermogravimetric Analysis (TGA)}

TGA was performed using a TGA Q500 instrument. The samples were placed in

Table 1. Composition of composites (all in weight \%).

\begin{tabular}{cccc}
\hline Sample & HDPE (wt.\%) & xGnPs (wt.\%) & n-MgO (wt.\%) \\
\hline Neat HDPE & 100 & 0 & 0 \\
HDPE-1G-2MgO & 97 & 1 & 2 \\
HDPE-2.5G-2MgO & 95.5 & 2.5 & 2 \\
HDPE-5G-2MgO & 93 & 5 & 2 \\
\hline
\end{tabular}


a platinum crucible and heated in a nitrogen-filled environment with a heating rate of $20^{\circ} \mathrm{C} / \mathrm{min}$ from room temperature to $600^{\circ} \mathrm{C}$. The initial weights of the samples were approximately $22 \mathrm{mg}$. The data extracted from the test were used to plot both the weight loss as a function of temperature and the thermogravimetric analysis/derivative thermal gravimetry (TGA/DTG) relations.

\section{Results and Discussions}

\subsection{X-Ray Diffraction Analysis}

Wide angle X-ray diffraction (WAXD) is a widely applied technique in the study of intercalation or exfoliation and has an advantage for composite characterization. X-ray diffraction (XRD) is used to explain the intercalation or exfoliation structures by utilizing methods for the inter-gallery spacing calculations, which are responsible for identification of the composite structures [2]. Using this technique, it is useful to identify and present the amount of inter-planner spacing (d-spacing) of the inter-gallery for different particle loading composites as well as for the neat polymer.

Figure 1 shows the XRD patterns of the neat HDPE and HDPE/xGnP/n-MgO composites with different amounts of fillers. From the XRD patterns obtained, $\mathrm{xGnP}$ and $\mathrm{n}-\mathrm{MgO}$ were found in samples $\mathrm{b}$ to $\mathrm{d}$, as shown in Figure 1. It is clear that the $\mathrm{xGnP}$ peaks were detected ata two theta of $26.6^{\circ}$ in all composite samples, which matches the previous study [23]. In contrast, $\mathrm{n}-\mathrm{MgO}$ was observed at a two theta of $42.9^{\circ}$, which suggests the face-centred cubic crystalline phase (JCPDS No 45-0496) [24]. In addition, the intensity of the $\mathrm{xGnP}$ peak became stronger with increasing amounts of $\mathrm{xGnP}$ added into the HDPE matrix, whereas the intensity of the $\mathrm{n}-\mathrm{MgO}$ peak was relatively consistent, as shown in Figure 1. Table 2 represents the change of the basal spacing $\left(\mathrm{d}_{001}\right.$ spacing $)$ of the composites, which was calculated by Bragg's Law using the values extracted from the XRD patterns according to literature [25]. The d-spacing can be described as

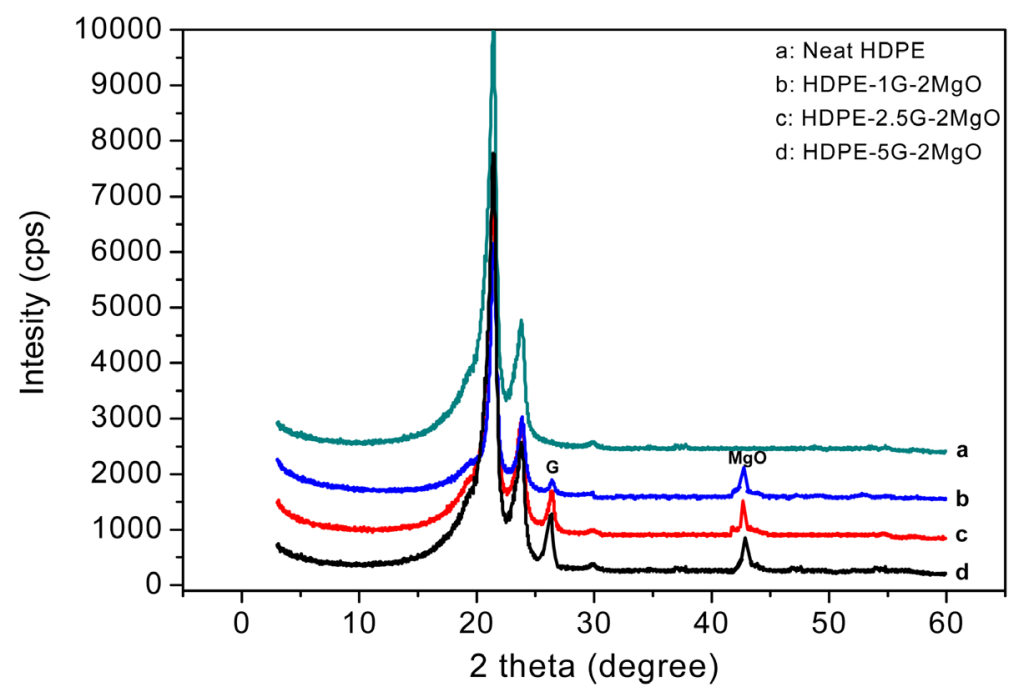

Figure 1. XRD patterns of neat HDPE and its composites. 
Table 2. XRD d-spacings of various HDPE and its nanocomposite samples.

\begin{tabular}{ccc}
\hline Samples & 2 Theta & d-spacing $[\AA]$ \\
\hline 100 wt. \% HDPE & 21.48 & 4.13 \\
HDPE/1xGnP/2n-MgO & 21.50 & 4.12 \\
HDPE/2.5xGnP/2n-MgO & 21.53 & 4.12 \\
HDPE/5xGnP/2n-MgO & 21.52 & 4.12 \\
\hline
\end{tabular}

the distance between planes of atoms that gives rise to diffraction peaks. Each peak in a diffractogram results from a corresponding d-spacing. The planes of atoms can be referred to as a $3 \mathrm{D}$ coordinate system and can be described as a direction within the crystal. Therefore, the d-spacing, in addition to having a dimension, which is usually given in Ångstroms, can be labelled with a plane direction, hkl. With the development of nanotechnology, an increasing number of materials with $\mathrm{d}$-spacings in the nanometre range have been made.

\subsection{Fourier Transform Infrared (FTIR) Analysis}

Figure 2 shows the FTIR spectra of neat HDPE and its composites. The peak of HDPE was somewhat altered with the addition of graphite and a constant amount of magnesium oxide nanoparticles. The absorbance level was slightly decreased by the incorporation of high amounts of graphite. The reduction was not significant as the molecular structure was relatively constant. In summary, differences in the peaks of the composites were not clearly observed, which indicates the stability of the polymer molecular structure. Of note in this paper, the FTIR spectra are presented as the absorbance percentage as a function of wavelength, not as the transmittance percentage as a function of wavelength. Therefore, if we carefully look at the FTIR spectra, the spectra show a decrease in the absorbance percentage with increasing filler content. Furthermore, this decrease in intensity can be attributed to a decrease in the number of free polyethylene chains, meaning a number of the polymer chains were coordinated to the carbon particles, and hence, the flexibility and molecular motion of the polymer chain are restricted.

\subsection{Thermal Properties}

The TGA/DTG analysis of monolithic HDPE and HDPE/xGnP/n-MgO composites during heating from $20^{\circ} \mathrm{C}$ to $600^{\circ} \mathrm{C} / \mathrm{min}$ are shown in Figure 3. From Figure 3, it is clear that the addition of graphite and magnesium oxide nanoparticles into the HDPE matrix resulted in a slight increase in the thermal stability. Additionally, the onset temperature of the neat polymer was $465^{\circ} \mathrm{C}$, whereas for $\mathrm{HDPE} / 1 \mathrm{xGnP} / 2 \mathrm{n}-\mathrm{MgO}$ and $\mathrm{HDPE} / 2.5 \mathrm{xGnP} / 2 \mathrm{n}-\mathrm{MgO}$, the onset temperatures were $464^{\circ} \mathrm{C}$ and $464^{\circ} \mathrm{C}$, respectively. By incorporating $5 \mathrm{wt} . \%$ graphite and 2 wt.\% magnesium oxide into the HDPE matrix, the onset temperature was improved to $466^{\circ} \mathrm{C}$. The char yield of the composites was significantly increased in a manner proportional to the graphite content. Crystallinity tended to be reduced 


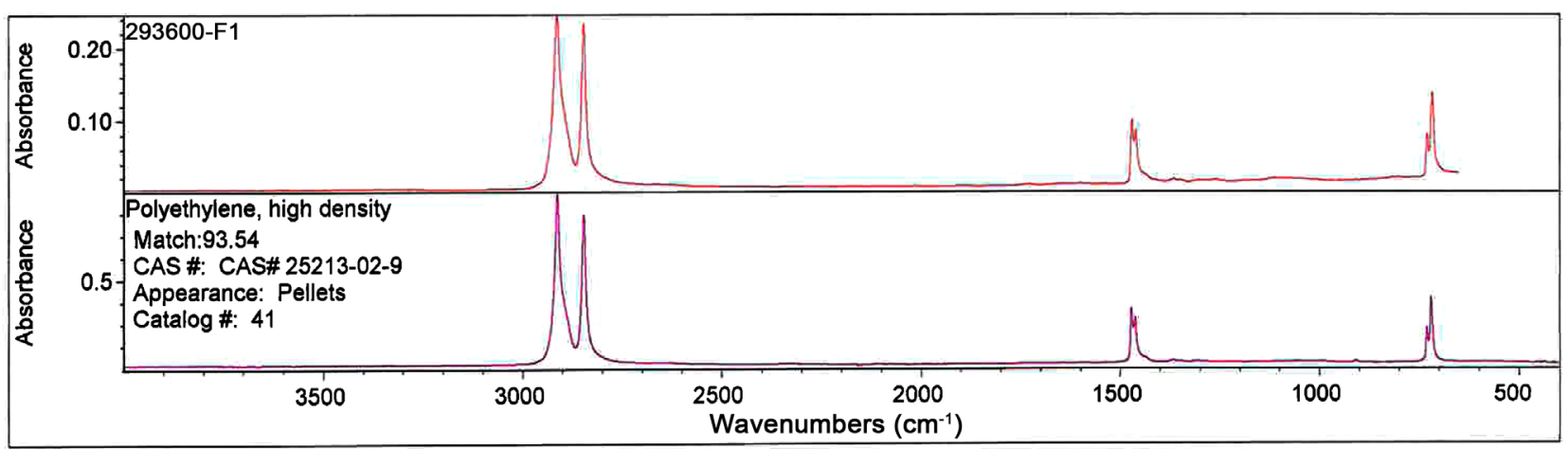

(a)

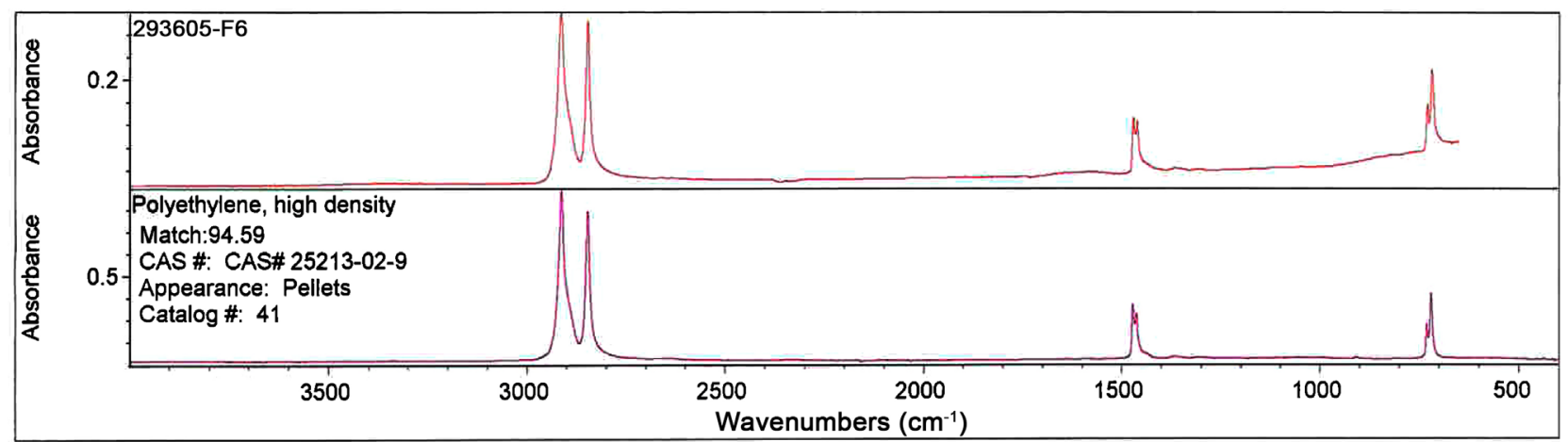

(b)

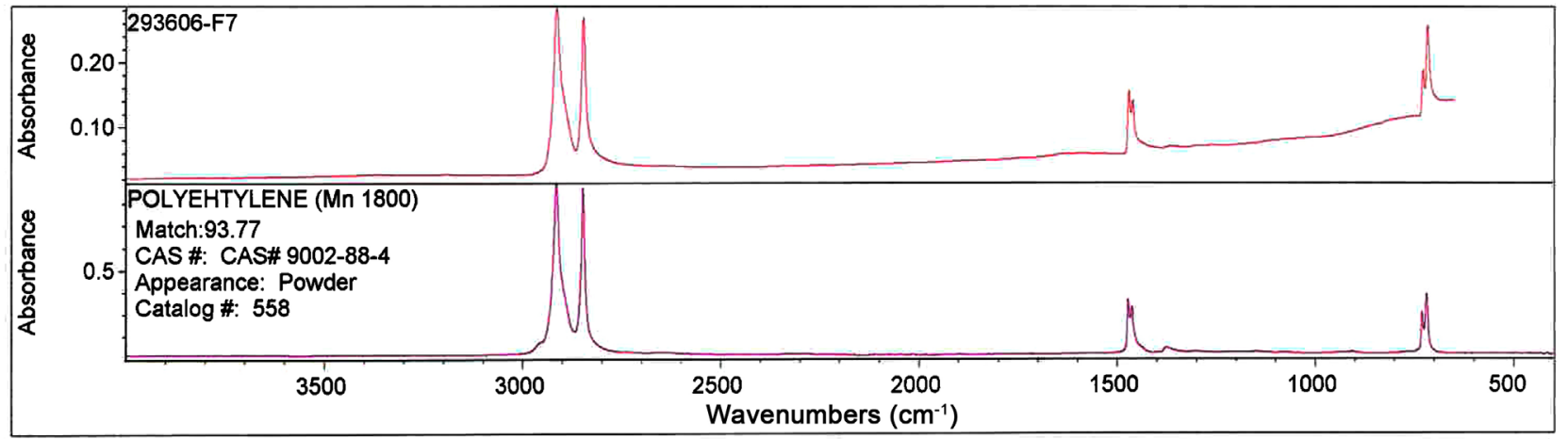

(c)

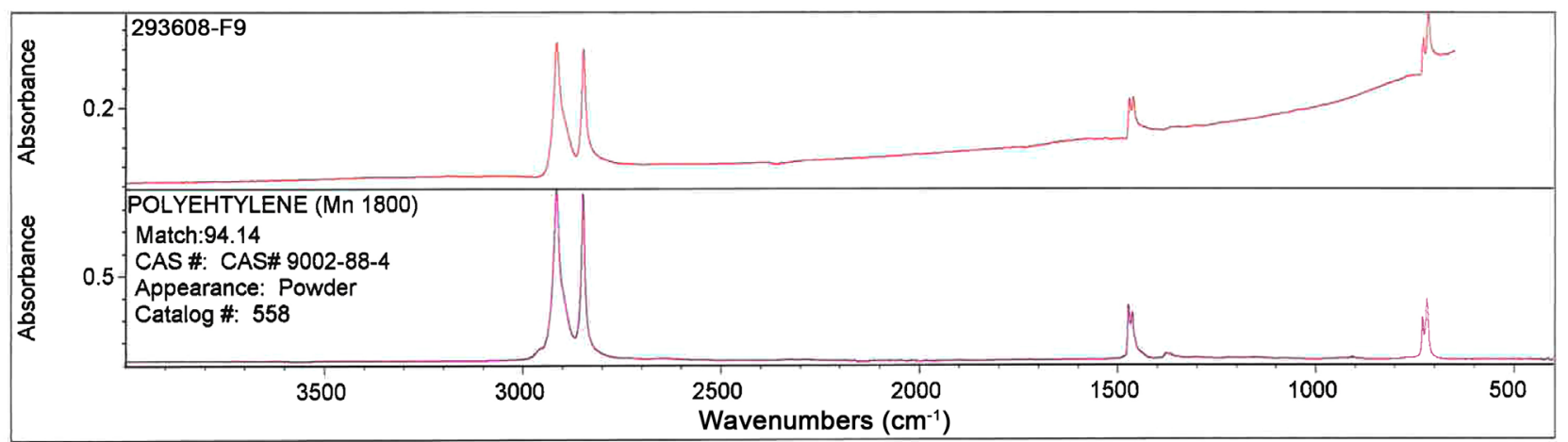

(d)

Figure 2. FTIR images of HDPE and its composites: (a) 100 wt.\% HDPE, (b) HDPE/1xGnP/2n-MgO, (c) HDPE/2.5xGnP/2n$\mathrm{MgO}$, and (d) $\mathrm{HDPE} / 10 \mathrm{xGnP} / 2 \mathrm{n}-\mathrm{MgO}$ (too bad resolution-not clear). 


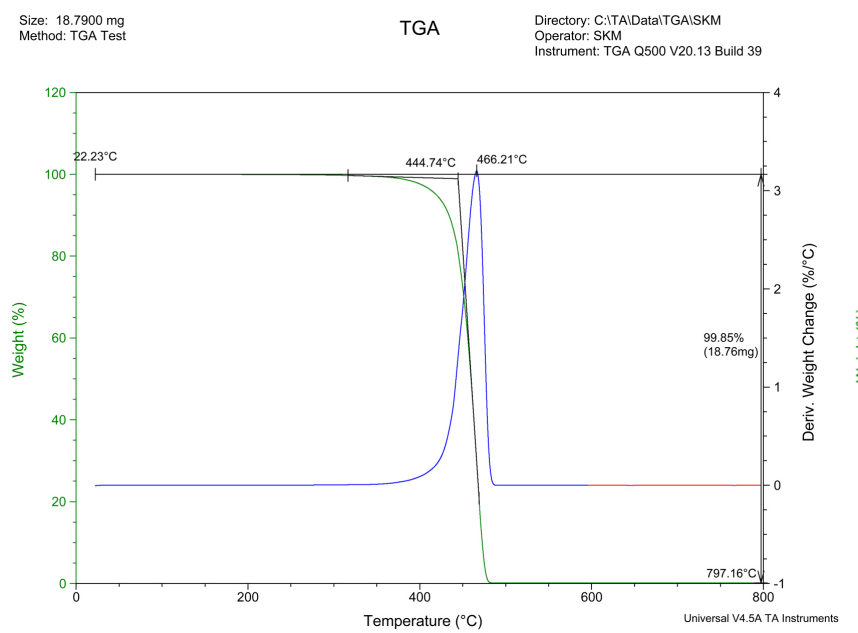

(a)

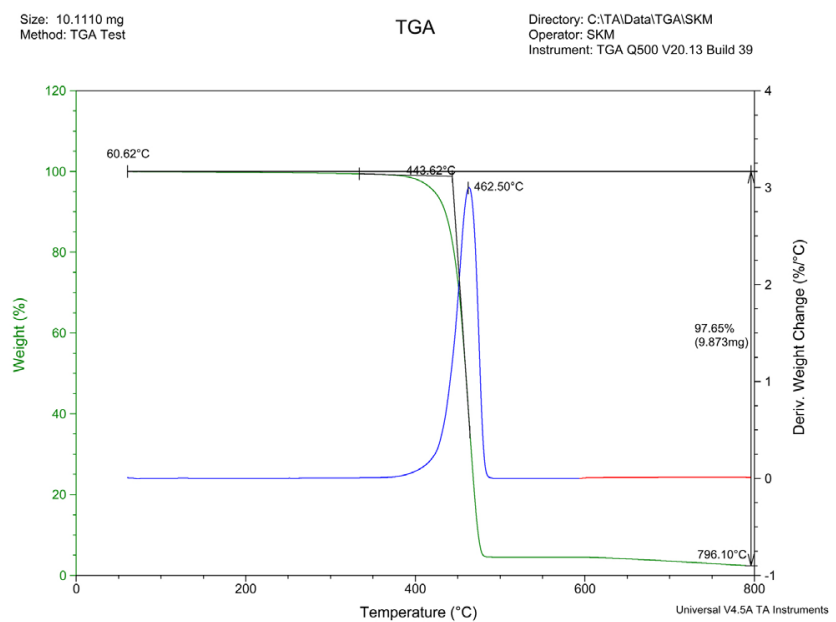

(c)

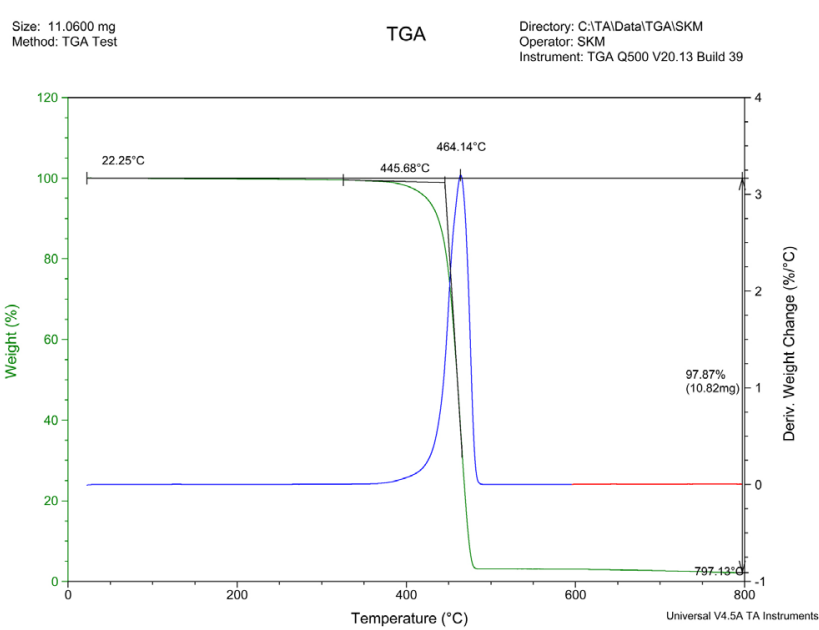

(b)

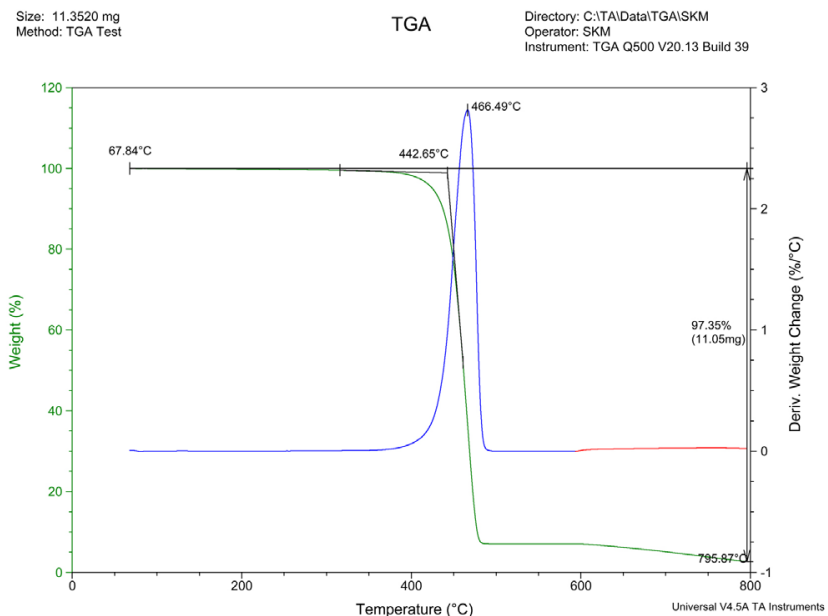

(d)

Figure 3. TGA results of (a) 100 wt.\% HDPE, (b) HDPE/1xGnP/2n-MgO, (c) HDPE/2.5xGnP/2n-MgO, and (d) HDPE/5xGnP/ $2 \mathrm{n}-\mathrm{MgO}$.

by increasing the composite loading, as shown in Table 3, which agreed with the literature that composites with plate-like particles have a reduced degree of crystallinity [26]. There is a robust relationship between Figure 3 and Table 3. The melting temperature ( $\mathrm{Tm})$, crystallization temperature $(\mathrm{Tc})$ and degree of crystallinity are observed and calculated from the TGA curves.

These findings are in close agreement with those in the study by Wegrzyn et al. [27].

\subsection{Microstructure}

To investigate the surface morphology of the composites, SEM micrographs were taken for the monolithic HDPE and HDPE-xGnP/n-MgO composites, as shown in Figure 4. Figure 4(a) reveals some white strand regions as a characteristic of polymer materials. The composites with 1 and 2.5 wt.\% xGnP exhibited good dispersion/distribution of fillers in the matrix, which shows no evidence 
Table 3. Thermal properties of HDPE and its corresponding composites.

\begin{tabular}{cccc}
\hline Samples & $\operatorname{Tm}\left({ }^{\circ} \mathrm{C}\right)$ & $\operatorname{Tc}\left({ }^{\circ} \mathrm{C}\right)$ & Crystallinity (\%) \\
\hline 100 wt.\% HDPE & 131 & 117 & 62.83 \\
$\mathrm{HDPE} / 1 \mathrm{xGnP} / 2 \mathrm{n}-\mathrm{MgO}$ & 131.53 & 117.31 & 62.22 \\
$\mathrm{HDPE} / 2.5 \mathrm{xGnP} / 2 \mathrm{n}-\mathrm{MgO}$ & 130 & 118 & 61.6 \\
$\mathrm{HDPE} / 5 \mathrm{xGnP} / 2 \mathrm{n}-\mathrm{MgO}$ & 118.74 & 130 & 61.5 \\
\hline
\end{tabular}
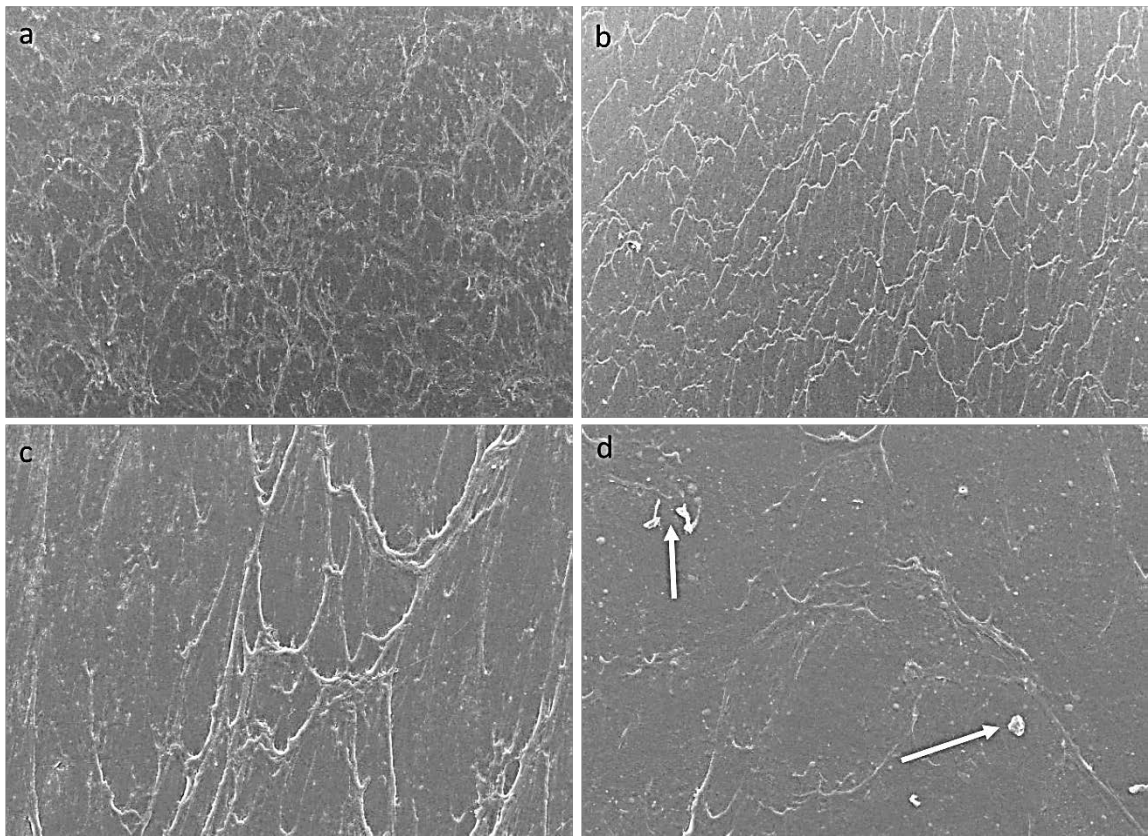

Figure 4. SEM images of HDPE and its composites: (a) 100 wt.\% HDPE (2 mm), (b) $\mathrm{HDPE} / 1 \mathrm{xGnP} / 2 \mathrm{n}-\mathrm{MgO}(2 \mathrm{~mm}),(\mathrm{c}) \mathrm{HDPE} / 2.5 \mathrm{xGnP} / 2 \mathrm{n}-\mathrm{MgO}(400 \mu \mathrm{m})$, and (d) HDPE/ $5 \mathrm{xGnP} / 2 \mathrm{n}-\mathrm{MgO}(400 \mu \mathrm{m})$.

of aggregation. This is due to the high affinity between the particles and polymer during fabrication at the optimal injection conditions. Furthermore, less intercalation was obtained in the polymers with the addition of $5 \mathrm{wt} . \% \mathrm{xGnP}$, which could be associated with eitherparticle agglomeration or the possibility of losing the platelet morphology of $\mathrm{xGnP}$, leading to the development of a rolled-up structure or folds during preparation and dispersion differences [3]. It is worth mentioning here that achieving a homogeneous dispersion is the most challenging obstacle in obtaining an efficient reinforced polymer, especially in the case of non-polar polymers such as polyethylene (PE) [2] [28].

\section{Conclusion}

$\mathrm{HDPE} / \mathrm{xGnP} / \mathrm{n}-\mathrm{MgO}$ composites were fabricated using an injection moulding machine. The present results show that the combination of $\mathrm{xGnP}$ and $\mathrm{n}-\mathrm{MgO}$ filler provides varying degrees of reduction in the thermal properties of composites. Generally, all of the composite samples revealed lower thermal properties compared with the monolithic HDPE. This reduction can be attributed to the 
agglomeration of particles within the matrix as a consequence of inadequate matrix-reinforcement adhesion. Other preparation method such as in situ polymerization, can be utilised for investigating the intercalation level.

\section{Acknowledgements}

The author would like to thank SABIC for their assistantship and tremendous help and contribution in the preparation of the composites and their characterization.

\section{Conflicts of Interest}

The author declares no conflicts of interest regarding the publication of this paper.

\section{References}

[1] Noor Hasanah, T., Wijeyesekera, D.C., Lim, A. and Ismail, B. (2014) Recycled PP/HDPE Blends: A Thermal Degradation and Mechanical Properties Study. Applied Mechanics and Materials, 465, 932-936.

[2] Alateyah, A.I., Dhakal, H.N. and Zhang, Z.Y. (2013) Processing, Properties, and Applications of Polymer Nanocomposites Based on Layer Silicates: A Review. Advances in Polymer Technology, 32. https://doi.org/10.1002/adv.21368

[3] Jiang, X. and Drzal, L.T. (2010) Multifunctional High Density Polyethylene Nanocomposites Produced by Incorporation of Exfoliated Graphite Nanoplatelets 1: Morphology and Mechanical Properties. Polymer Composites, 31, 1091-1098.

[4] Pedrazzoli, D., Pegoretti, A. and Kalaitzidou, K. (2014) Synergistic Effect of Exfoliated Graphite Nanoplatelets and Short Glass Fiber on the Mechanical and Interfacial Properties of Epoxy Composites. Composites Science and Technology, 98, 15-21. https://doi.org/10.1016/j.compscitech.2014.04.019

[5] Alam, S.N. and Kumar, L. (2016) Mechanical Properties of Aluminium Based Metal Matrix Composites Reinforced with Graphite Nanoplatelets. Materials Science and Engineering: A, 667, 16-32. https://doi.org/10.1016/j.msea.2016.04.054

[6] Karevan, M., Eshraghi, S., Gerhardt, R., Das, S. and Kalaitzidou, K. (2013) Effect of Processing Method on the Properties of Multifunctional Exfoliated Graphite Nanoplatelets/Polyamide 12 Composites. Carbon, 64, 122-131. https://doi.org/10.1016/j.carbon.2013.07.043

[7] Li, Y., Zhang, H., Porwal, H., Huang, Z., Bilotti, E. and Peijs, T. (2017) Mechanical, Electrical and Thermal Properties of In-Situ Exfoliated Graphene/Epoxy Nanocomposites. Composites Part A: Applied Science and Manufacturing, 95, 229-236. https://doi.org/10.1016/j.compositesa.2017.01.007

[8] Wang, F., Drzal, L.T., Qin, Y. and Huang, Z. (2016) Enhancement of Fracture Toughness, Mechanical and Thermal Properties of Rubber/Epoxy Composites by Incorporation of Graphene Nanoplatelets. Composites Part A: Applied Science and Manufacturing, 87, 10-22. https://doi.org/10.1016/j.compositesa.2016.04.009

[9] Rath, T. and Li, Y. (2011) Nanocomposites Based on Polystyrene-b-Poly(ethylener-butylene)-b-Polystyrene and Exfoliated Graphite Nanoplates: Effect of Nanoplatelet Loading on Morphology and Mechanical Properties. Composites Part A: Applied Science and Manufacturing, 42, 1995-2002. https://doi.org/10.1016/j.compositesa.2011.09.002 
[10] Chung, D. (2002) Review Graphite. Journal of Materials Science, 37, 1475-1489. https://doi.org/10.1023/A:1014915307738

[11] Kalaitzidou, K., Fukushima, H. and Drzal, L.T. (2007) A New Compounding Method for Exfoliated Graphite-Polypropylene Nanocomposites with Enhanced Flexural Properties and Lower Percolation Threshold. Composites Science and Technology, 67, 2045-2051. https://doi.org/10.1016/j.compscitech.2006.11.014

[12] Kim, S., Seo, J. and Drzal, L.T. (2010) Improvement of Electric Conductivity of LLDPE Based Nanocomposite by Paraffin Coating on Exfoliated Graphite Nanoplatelets. Composites Part A: Applied Science and Manufacturing, 41, 581-587. https://doi.org/10.1016/j.compositesa.2009.05.002

[13] Mantilaka, M., Pitawala, H., Karunaratne, D. and Rajapakse, R. (2014) Nanocrystalline Magnesium Oxide from Dolomite via Poly (Acrylate) Stabilized Magnesium Hydroxide Colloids. Colloids and Surfaces A: Physicochemical and Engineering Aspects, 443, 201-208. https://doi.org/10.1016/j.colsurfa.2013.11.020

[14] Abdizadeh, H., Ebrahimifard, R. and Baghchesara, M.A. (2014) Investigation of Microstructure and Mechanical Properties of Nano MgO Reinforced Al Composites Manufactured by Stir Casting and Powder Metallurgy Methods: A Comparative Study. Composites Part B: Engineering, 56, 217-221.

https://doi.org/10.1016/j.compositesb.2013.08.023

[15] Bourbigot, S., Gilman, J.W. and Wilkie, C.A. (2004) Kinetic Analysis of the Thermal Degradation of Polystyrene-Montmorillonite Nanocomposite. Polymer Degradation and Stability, 84, 483-492. https://doi.org/10.1016/j.polymdegradstab.2004.01.006

[16] Dabrowski, F., Bourbigot, S., Delobel, R. and Le Bras, M. (2000) Kinetic Modelling of the Thermal Degradation: of Polyamide-6 Nanocomposite. European Polymer Journal, 36, 273-284. https://doi.org/10.1016/S0014-3057(99)00079-8

[17] Holland, B. and Hay, J. (2001) The Thermal Degradation of Poly (Vinyl Alcohol). Polymer, 42, 6775-6783. https://doi.org/10.1016/S0032-3861(01)00166-5

[18] Blumstein, A. (1965) Polymerization of Adsorbed Monolayers. II. Thermal Degradation of the Inserted Polymer. Journal of Polymer Science Part A: General Papers, 3, 2665-2672. https://doi.org/10.1002/pol.1965.100030721

[19] Shalwan, A., Alateyah, A., Aldousiri, B. and Alajmi, M. (2016) Thermal and Nanoindentation Behaviours of Layered Silicate Reinforced Recycled GF-12 Nanocomposites. Journal of Materials Science Research, 5, 10. https://doi.org/10.5539/jmsr.v5n4p10

[20] Alateyah, A. (2018) Thermal Properties and Morphology of Polypropylene Based on Exfoliated Graphite Nanoplatelets/Nanomagnesium Oxide. Open Engineering, 8, 432-439.

[21] Giannelis, E.P. (1996) Polymer Layered Silicate Nanocomposites. Advanced Materials, 8, 29-35. https://doi.org/10.1002/adma.19960080104

[22] Chen, Y., Zhou, S., Yang, H. and Wu, L. (2005) Structure and Properties of Polyurethane/Nanosilica Composites. Journal of Applied Polymer Science, 95, 1032-1039. https://doi.org/10.1002/app.21180

[23] Geng, Y., Wang, S.J. and Kim, J.-K. (2009) Preparation of Graphite Nanoplatelets and Graphene Sheets. Journal of Colloid and Interface Science, 336, 592-598. https://doi.org/10.1016/j.jcis.2009.04.005

[24] Song, P., Cao, Z., Cai, Y., Zhao, L., Fang, Z. and Fu, S. (2011) Fabrication of Exfoliated Graphene-Based Polypropylene Nanocomposites with Enhanced Mechanical and Thermal Properties. Polymer, 52, 4001-4010. 
https://doi.org/10.1016/j.polymer.2011.06.045

[25] Mittal, G., Dhand, V., Rhee, K.Y., Park, S.-J. and Lee, W.R. (2015) A Review on Carbon Nanotubes and Graphene as Fillers in Reinforced Polymer Nanocomposites. Journal of Industrial and Engineering Chemistry, 21, 11-25.

https://doi.org/10.1016/j.jiec.2014.03.022

[26] Pavlidou, S. and Papaspyrides, C.D. (2008) A Review on Polymer-Layered Silicate Nanocomposites. Progress in Polymer Science, 33, 1119-1198.

https://doi.org/10.1016/j.progpolymsci.2008.07.008

[27] Wegrzyn, M., Galindo, B., Benedito, A. and Gimenez, E. (2015) Morphology, Thermal, and Electrical Properties of Polypropylene Hybrid Composites Co-Filled with Multi-Walled Carbon Nanotubes and Graphene Nanoplatelets. Journal of Applied Polymer Science, 132. https://doi.org/10.1002/app.42793

[28] Alateyah, A.I., Dhakal, H.N. and Zhang, Z.Y. (2014) Water Absorption Behaviour, Mechanical and Thermal Properties of Vinyl Ester Matrix Nanocomposites Based on Layered Silicate. Polymer-Plastics Technology and Engineering, 53, 1-17.

https://doi.org/10.1080/03602559.2013.844246 